\title{
K ATP Associated Transient Neonatal Diabetes Mellitus
}

National Cancer Institute

\section{Source}

National Cancer Institute. K ATP Associated Transient Neonatal Diabetes Mellitus. NCI

Thesaurus. Code C131846.

K ATP channel-associated neonatal diabetes mellitus that resolves spontaneously. 